\title{
DIAGNÓSTICO DAS LEIS ESTADUAIS DE INCENTIVO AO ESPORTE NO BRASIL
}

\author{
DIAGNOSIS OF STATE SPORTS INCENTIVE LAWS IN BRAZIL
}

\section{DIAGNÓSTICO DE LAS LEYES ESTADUALES DE INCENTIVOS DEPORTIVOS EN BRASIL}

\author{
Sabrina de Lima Vitório \\ https://orcid.org/0000-0002-1942-4562 (iD \\ http://lattes.cnpq.br/4841009979299818 \\ Universidade Estadual de Campinas (Campinas, SP - Brasil) \\ sabrinavitoriome@gmail.com \\ Leandro Eduardo Cerbi \\ https://orcid.org/0000-0002-5851-6195 (iD) \\ http://lattes.cnpq.br/6923363847785665 \\ Centro Universitário Anhanguera Educacional (Leme, SP - Brasil) \\ leandrocerbi@gmail.com \\ Bruna Lindman Bueno \\ https://orcid.org/0000-0002-0204-4176 (D) \\ http://lattes.cnpq.br/6219243742095509 9 \\ Universidade de São Paulo (São Paulo, SP - Brasil) \\ brunabueno@usp.br \\ Clara Sanchez da Trindade Santos \\ https://orcid.org/0000-0002-0634-0407 \\ http://lattes.cnpq.br/4366856495261782 \\ Universidade Estadual de Campinas (Campinas, SP - Brasil) \\ clarasanchez.ce@gmail.com \\ Leandro Carlos Mazzei \\ https://orcid.org/0000-0002-0788-4668 (iD \\ http://lattes.cnpq.br/6222841355609478 9 \\ Universidade Estadual de Campinas (Campinas, SP - Brasil) \\ lemazzei@unicamp.br
}

\begin{abstract}
Resumo
Com a criação da Lei Federal de Incentivo ao Esporte em 2006 e na onda dos Megaeventos Esportivos no Brasil, muitos Estados criaram suas próprias iniciativas relacionadas à isenção fiscal para favorecimento do Esporte. No entanto, a bibliografia sobre este fenômeno é escassa. Assim, este estudo teve por objetivo apresentar um diagnóstico das Leis de Incentivo ao Esporte (LIEs) no âmbito Estadual, indicando as características destas ações realizadas pelas unidades federativas. Trata-se de um estudo de caráter descritivo, utilizando de fontes documentais para a coleta de dados obtidas através dos sites oficiais de cada Secretaria ou órgão semelhante responsável pelas Políticas Públicas do Esporte nos Estados. Foram identificadas ações relacionadas ao incentivo do esporte via isenção fiscal em 15 Estados e todas envolvem o tributo ICMS. Verificou-se ainda uma variação grande com relação às porcentagens de valor destinadas, bem como uma diversificação das manifestações esportivas em cada Estado. Palavras-chave: Leis Estaduais de Incentivo ao Esporte; Políticas Públicas; Esporte.
\end{abstract}




\begin{abstract}
With the creation of the Federal Sports Incentive Law in 2006 and the Sporting Mega-Events held in Brazil, many states have created their own initiatives related to tax exemption to favor Sports. However, the bibliography on this phenomenon is scarce. Therefore, this study aimed to present a diagnosis of the Sports Incentive Laws at the State level, indicating the actions carried out by the federative units and their main characteristics. This is a descriptive study, using documental sources for data collection obtained through the official websites of each Secretariat or similar body responsible for the Sports Public Policies in the Brazilian States. Were identified 15 States actions related to the incentive to sports via tax exemption and all of them from the 'ICMS' tribute. It was also verified a large variation regarding the percentages of value allocated, as well as a great diversification of the sports manifestations in each State.
\end{abstract}

Keywords: Tax Exemption Laws; Public Policy; Sport.

\title{
Resumen
}

Con la creación de la Ley Federal de Incentivo al Deporte y con los Mega-Eventos Deportivos en Brasil, muchos Estados Brasileños crearon sus iniciativas para favorecer el deporte a través de exenciones fiscales. Sin embargo, la bibliografía sobre este fenómeno es escasa. Por lo tanto, este estudio tuvo como objetivo presentar un diagnóstico de las Leyes de Incentivo al Deporte a nivel de los Estados Brasileños, indicando sus principales características. Se trata de un estudio descriptivo, que utiliza fuentes documentales obtenidos a través de los sitios web oficiales de cada Secretaría u organismo similar responsable de las Políticas Públicas de Deporte en los Estados. Se identificaron acciones relacionadas con el incentivo desportivo en 15 Estados y todos ellos relacionados com el impuestos ICMS. También se verificó una gran variación en cuanto a los porcentajes de valor destinados, así como una diversificación de las manifestaciones deportivas en cada Estado.

Palabras clave: Leyes de Exención de Impuestos; Política Pública; Deporte.

\section{INTRODUÇÃO}

Qualquer temática relacionada às Políticas Públicas é complexa, pois é frequente a ausência de consensos absolutos, bem como a existência de divergências conceituais na literatura e interpretações relacionadas às práticas desta área (SECCHI; COELHO; PIRES, 2020). Por exemplo, para Secchi, Coelho e Pires (2020), os diferentes olhares sobre as Políticas Públicas permitem que esta área possa ser considerada como segmento de atuação exclusiva do Estado, o que pode ser nomeado como uma abordagem estatista. A exclusividade estatal quanto às Políticas Públicas é derivada da superioridade objetiva do Estado em fazer leis e fazer com que a sociedade as cumpra em prol dela mesma e da manutenção do Estado de Direito. Além desse argumento objetivo, há o fato de que o Estado tenha superioridade hierárquica para corrigir desvirtuamentos que dificilmente o mercado e a comunidade conseguem corrigir sozinhos. A abordagem estatista até admite que atores não estatais influenciem no processo de elaboração e implementação de políticas públicas, mas não confere a eles o privilégio de estabelecer (decidir) e liderar um processo de política pública (SECCHI; COELHO; PIRES, 2020).

Ainda segundo Secchi, Coelho e Pires (2020), as Políticas Públicas podem ter um olhar pragmático, como a definição de que as políticas podem ser consideradas tudo aquilo 
que os governos escolhem fazer ou não fazer (omissão ou a negligência neste último caso) ou ainda posicionamentos teóricos que interpretam as Políticas Públicas como diretrizes estruturantes, envolvendo um conjunto de programas, planos e projetos em níveis estratégicos (mais abrangentes) quanto operacionais (mais locais). Para além da abordagem estatista, outro ponto de vista sobre as Políticas Públicas envolve uma abordagem multicêntrica ou policêntrica, que considera o protagonismo de organizações privadas e organizações não governamentais para o estabelecimento das Políticas Públicas, juntamente com o papel dos órgãos estatais (SECCHI; COELHO; PIRES, 2020).

Tanto a abordagem estatista como a abordagem multicêntrica podem ser identificadas nas Políticas Públicas do Esporte no Brasil nas últimas décadas. Se de um lado alguns órgãos do poder executivo majoritariamente propunham legislações, principalmente para financiamento do esporte (e por vezes sua governança), do outro, boa parte de nosso "sistema" esportivo é composto por organizações privadas (majoritariamente associações sem fins lucrativos), como por exemplo o Comitê Olímpico do Brasil (COB) e o Comitê Paralímpico Brasileiro (CPB), dentre outros (MEIRA; BASTOS; BÖHME, 2012).

Na Constituição Federal do Brasil e na Lei 9.615 de 1998 se identificam os respectivos dizeres: "a autonomia das entidades desportivas dirigentes e associações, quanto a sua organização e funcionamento" e "autonomia, definido pela faculdade e liberdade de pessoas físicas e jurídicas organizarem-se para a prática desportiva" (BRASIL, 1988, 1998). E de fato, a partir destes documentos e ao longo dos anos posteriores, as Políticas Públicas para o Esporte e suas respectivas legislações foram formuladas e implementadas principalmente com propósitos relacionados com o repasse de recursos para organizações não governamentais, estabelecimento de suporte para atletas, e possibilidades de fomento para projetos esportivos com isenção fiscal para a iniciativa privada. Respectivamente, pode-se destacar as ainda vigentes: Lei 10.264/01 (repasse de arrecadação das loterias federais para o esporte) (BRASIL, 2001); Lei no 10.891/04 que instituiu o programa "Bolsa Atleta" em nível nacional (BRASIL, 2004) e Lei 11.438/06, conhecida como Lei de Incentivo ao Esporte (BRASIL, 2006).

Para Salinas (2012), a elaboração de leis muitas vezes tem como propósito o desenvolvimento de um elemento estruturador das ações administrativas e de uma maior possibilidade para a efetividade/continuidade de Políticas Públicas (SALINAS, 2012). Assim, as leis se constituem como diretrizes a serem observadas pelos atores envolvidos no contexto da implementação das Políticas Públicas, ou seja, as leis prescrevem o curso da ação que será 
dado para a implementação das Políticas Públicas. São nelas que estão resumidas as instruções aos administradores públicos, outros atores e membros da sociedade, os quais na condição de envolvidos, devem agir em prol da realização dos objetivos estabelecidos no desenvolvimento das ações perante ao problema identificado (SALINAS, 2012). Tais fatos independem de uma abordagem estatista ou multicêntrica.

Especialmente sobre as leis que envolvem possibilidade de isenção fiscal em prol de algum serviço ou atividade esportiva, a iniciativa de âmbito Federal foi criada enquanto legislação para, originalmente, dar maiores possibilidades ao fomento do esporte no Brasil. Tal iniciativa ainda hoje é reconhecida pela sociedade como "Lei de Incentivo ao Esporte" (LIE). Sua assinatura aconteceu no ano de 2006, momento em que o Brasil se preparava para sediar os Jogos Pan-americanos e Parapan-americanos de 2007, e depois almejar sua candidatura para outros eventos esportivos internacionais (Jogos Olímpicos e Paralímpicos por exemplo). Enquanto Política Pública, a LIE Federal possibilita que pessoas físicas (PF) e jurídicas (PJ) destinem uma parcela do imposto de renda devido (6\% e $1 \%$, respectivamente) "diretamente" à e em benefício de projetos esportivos previamente aprovados. Os projetos são executados e gerenciados por organizações públicas e privadas do setor, servindo como mais uma estratégia para o desenvolvimento ou possibilidade de investimento no esporte brasileiro (BASTIDAS; BASTOS, 2011; MATIAS et al., 2015; SANTOS; JUCHEM; MADURO, 2017).

Diversos estudos foram desenvolvidos no sentido de se avaliar sob diferentes aspectos a LIE Federal, seja para análise dos montantes de projetos aprovados (CAVAZZONI; BASTOS, 2010); para a verificação de quais manifestações esportivas foram mais beneficiadas pela Lei (BASTIDAS; BASTOS, 2011); os problemas de efetividade quanto ao propósito da própria Lei (MATIAS et al., 2015); e também alguns panoramas gerais da LIE Federal entre 2007 a 2011 ou 2007 à 2019 (NASCIMENTO, 2019; SANTOS; JUCHEM; MADURO, 2017). Basicamente esses estudos constataram problemas entre a aprovação e a captação de recursos pelos projetos; uma concentração de projetos e montantes captados na manifestação esportiva rendimento; de uma predominância de "grandes" proponentes na aprovação de projetos; dentre outros.

Partindo (supostamente) dos princípios da constitucionalidade e dos mesmos propósitos da LIE Federal, boa parte dos Estados da União e diversos municípios brasileiros desenvolveram suas próprias iniciativas relacionadas à isenção fiscal favorecendo projetos ligados ao esporte. Entretanto, há poucos estudos sobre essas iniciativas, assim como não 
existe um panorama geral para que futuros pesquisadores se debrucem com análises mais aprofundadas sobre Leis de Incentivo ao Esporte em contextos Estaduais ou Municipais.

Nesse sentido, podem ser feitos alguns questionamentos sobre este contexto, como por exemplo, todos os Estados brasileiros possuem Leis de Incentivo ao Esporte? As Leis de Incentivo ao Esporte em âmbito estadual possuem o mesmo propósito da legislação Federal? Que tipos de isenções fiscais são proporcionadas pelas LIEs Estaduais? Assim, com o propósito de responder a esses e outros questionamentos, o objetivo deste artigo será apresentar um diagnóstico das Leis de Incentivo ao Esporte em um âmbito Estadual e algumas de suas características. Serão identificados a existência ou não desta ação de Política Pública nos Estados, o ano de início da primeira com relação a este tipo de ação, sua característica (se Lei ou um Decreto), o imposto cedido ao "patrocinador", a porcentagem atual do imposto cedido para os projetos esportivos, as manifestações que são contempladas pela LIE identificada, o tipo de regularização legislativa da ação e de proponente que podem ser beneficiados pela mesma.

\section{MATERIAL E MÉTODOS}

A metodologia utilizada nesta pesquisa baseou-se na taxionomia apresentada por Vergara (2010), que subdivide os processos metodológicos em dois aspectos: primeiro quantos aos fins e segundo quanto aos meios. Quantos aos fins, a pesquisa se enquadra como descritiva, pois apresenta um diagnóstico das LIEs enquanto propostas de Políticas Públicas, neste caso, especificamente nos Estados brasileiros. Interessante citar que as pesquisas descritivas envolvem essa caracterização de um tema de estudo sem o objetivo direto de explicá-lo, mas que ao mesmo tempo podem estabelecer correlações entre variáveis servindo como base para possíveis explicações no futuro (MALHOTRA, 2011). Quantos aos meios, a pesquisa se enquadra como documental, visto que foram realizadas análises de documentos oficiais de cada Secretaria ou órgão semelhante que é responsável pelas Políticas Públicas do Esporte em cada Estado do Brasil.

Foram focos de identificação a existência ou não de uma Lei de Incentivo ao Esporte no contexto Estadual, o ano de início da primeira ação relacionada ao tema, o imposto cedido ao patrocinador que aportou recurso em algum projeto esportivo, a porcentagem atual do imposto cedido para os projetos esportivos, quais são as manifestações que são 
contempladas pela LIE identificada, além de sua caracterização/ enquadramento enquanto legislação e regularização quando ao tipo de proponente que pode ser beneficiado.

A coleta de dados se deu de outubro a novembro de 2020, e como critério de inclusão nas análises, que a LIE identificada existisse a pelo menos a dois anos. Primeiramente foram acessados os sites oficiais das Secretarias Estaduais de Esporte (ou órgão respectivo) de cada uma das 27 unidades federativas do país, além de pesquisa textual em site de busca com o termo - Lei de Incentivo Esporte "nome do Estado" - e a partir deles foi feito um levantamento referente à existência ou não de uma legislação para fomento do esporte a partir de isenção fiscal. Para tanto, conforme mencionado, nesse estudo foram levados em consideração legislações específicas (Leis Estaduais de Incentivo ao Esporte), legislações através de Fundos e também decretos regulamentadores. Feito esse levantamento, foi realizada a leitura de todas as legislações e decretos identificados a fim de obter dados a respeito dos mesmos (ano de criação, imposto cedido, porcentagem do imposto, tipo de proponente e manifestações esportivas contempladas).

Para o tratamento e análise dos dados foi realizada a aplicação de estatística descritiva (valores absolutos e porcentagem), através do programa Microsoft Office Excel 2016. Como os dados foram obtidos através de documentos de acesso público, não houve necessidade de autorização de comitê de ética para a realização deste estudo, apesar do mesmo fazer parte de uma pesquisa maior, que tem como CAAE o número 28709019.1.0000.5404.

\section{RESULTADOS E DISCUSSÃO}

Quanto à existência ou não de uma Lei de Incentivo ao Esporte em Estados brasileiros ou alguma normatização relacionada à esta temática, foi identificado que em 15 (55\%) dos 26 Estados brasileiros mais o Distrito Federal, possuem sua Política Pública própria neste tema. Sendo estes os Estados (em ordem alfabética): Acre, Bahia, Ceará, Goiás, Maranhão, Mato Grosso, Minas Gerais, Paraíba, Paraná, Pernambuco, Piauí, Rio de Janeiro, Rio Grande do Sul, Santa Catarina e São Paulo. A figura 1 ilustra esses resultados. 
Figura 1 - Estados que possuem uma Lei Estadual de Incentivo Fiscal ao Esporte

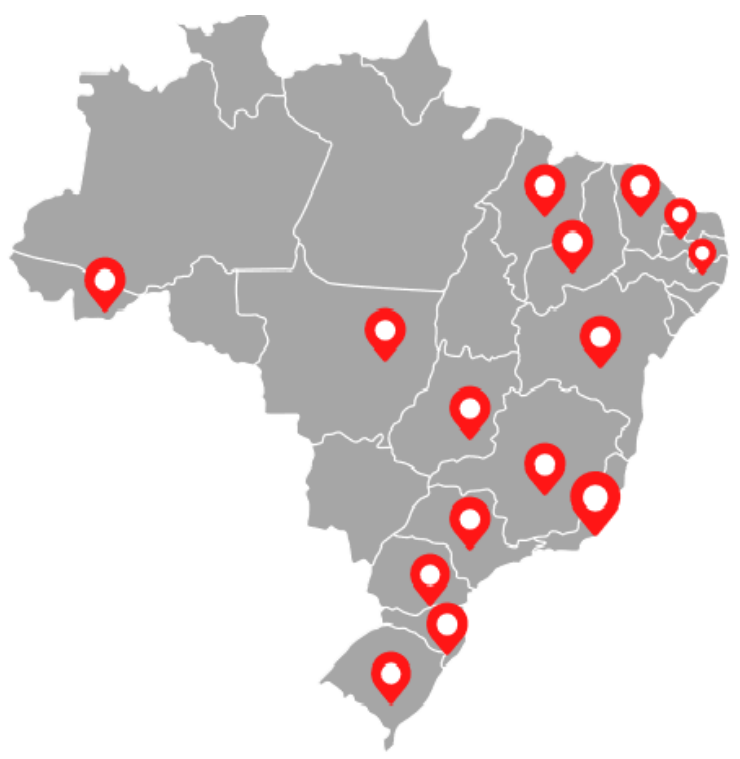

Fonte: construção dos autores.

Quanto ao ano de criação dessas ações, tributo envolvido nas isenções e manifestações esportivas a serem incentivadas no Estados identificados, foram obtidos os seguintes resultados, apresentados no Quadro 1 (em ordem alfabética).

Para além dos dados do Quadro 1, coletados até novembro de 2020, cabe mencionar que alguns Estados possuem Projetos-Lei sobre o tema, que são os casos do Amapá, Distrito Federal e Roraima. Outros Estados criaram (mais ainda não foram implementadas) suas legislações de Incentivo ao Esporte em 2021, como Espírito Santo e Rio Grande do Norte.

Com dados coletados até novembro de 2020 e com a existência de pelo menos dois anos, sobre o ano de criação, em boa parte dos Estados que possuem alguma ação próxima à iniciativa de LIE tiveram suas respectivas iniciativas iniciadas após o estabelecimento da legislação Federal, ou seja, a maioria das leis identificadas (9 do total de 15, ou seja, $60 \%$ ), surgiram após o ano de 2006. Por outro lado, e até de forma surpreendente, em alguns Estados já existia uma iniciativa para isenção fiscal em benefício ao esporte antes mesmo de 2006. Importante mencionar que muitas ações sofreram ajustes, alterações e atualizações ao longo dos anos. Destaque para o Estado do Rio de Janeiro, que teve uma primeira iniciativa sobre o tema analisado em 1992, passando por reformulação e nova legislação em 2018. 
Quadro 1 - Ano de criação, tributo e porcentagem envolvida e manifestações esportivas contempladas pelas ações relacionadas à Legislação para isenção fiscal em benefício ao esporte em nível Estadual.

\begin{tabular}{|c|c|c|c|}
\hline Estado & $\begin{array}{l}\text { Ano de Início } \\
\text { da Ação (LIE) }\end{array}$ & $\begin{array}{c}\text { Valores ou } \\
\text { Porcentagem ICMS }\end{array}$ & $\begin{array}{c}\text { Manifestações Esportivas que } \\
\text { podem ser contempladas }\end{array}$ \\
\hline $\begin{array}{c}\text { Acre } \\
\text { Lei } n^{\circ} 1.288 / 1999 \\
\end{array}$ & 1999 & Valores variados & Educacional, Participação e Rendimento \\
\hline $\begin{array}{c}\text { Bahia } \\
\text { Lei } \mathrm{n}^{\circ} 7.539 / 1999\end{array}$ & 1999 & Até $5,00 \%$ & Educacional, Participação e Rendimento \\
\hline $\begin{array}{c}\text { Ceará } \\
\text { Lei } n^{\circ} 15.700 / 2014 \\
\end{array}$ & 2014 & Até $2,00 \%$ & $\begin{array}{c}\text { Educacional, Participação, Rendimento e } \\
\text { Infraestrutura-Obras }\end{array}$ \\
\hline $\begin{array}{l}\text { Goiás } \\
\text { Lei } n^{\circ} 14.546 / 2003\end{array}$ & 2003 & No mínimo 5,00\% & $\begin{array}{l}\text { Educacional, Participação, Rendimento, } \\
\text { Infraestrutura, Eventos, Formação Esportiva, } \\
\text { Sócio Desportiva e Desenvolvimento Esportivo }\end{array}$ \\
\hline $\begin{array}{c}\text { Maranhão } \\
\text { Lei nº 9.436/2011 }\end{array}$ & 2011 & De 5,00 a $20,00 \%$ & $\begin{array}{c}\text { Educacional, Participação, Rendimento e } \\
\text { Infraestrutura / Obras, Eventos e Capacitação } \\
\text { Profissional }\end{array}$ \\
\hline $\begin{array}{c}\text { Mato Grosso } \\
\text { Lei } n^{\circ} 6.978 / 1997\end{array}$ & 1997 & $6,00 \%$ & Não foi possível identificar* \\
\hline $\begin{array}{c}\text { Minas Gerais } \\
\text { Lei } n^{\circ} 16.318 / 2006\end{array}$ & 2006 & $25,00 \%$ & $\begin{array}{c}\text { Educacional, Rendimento, Formação, Desporto } \\
\text { Social / Lazer e Desenvolvimento esportivo }\end{array}$ \\
\hline $\begin{array}{l}\text { Paraíba } \\
\text { Decreto } \mathrm{n}^{\circ} \\
29.054 / 2008\end{array}$ & 2008 & Até $5,00 \%$ & Competições, Eventos e Atividades Esportivas \\
\hline $\begin{array}{c}\text { Paraná } \\
\text { Lei } n^{\circ} 17.742 / 2013 \\
\end{array}$ & 2013 & De 0,50 a $3,00 \%$ & Formação, Participação e Rendimento \\
\hline $\begin{array}{c}\text { Pernambuco } \\
\text { Lei } n^{\circ} 15.706 / 2015\end{array}$ & 2015 & Até $5,00 \%$ & $\begin{array}{c}\text { Formação, Rendimento, Social, Capacitação, } \\
\text { Evento e Prêmios }\end{array}$ \\
\hline $\begin{array}{c}\text { Piauí } \\
\text { Lei } \mathrm{n}^{\circ} 5.315 / 2003 \\
\end{array}$ & 2003 & $0,25 \%$ & $\begin{array}{c}\text { Educacional, Participação, Rendimento e } \\
\text { Infraestrutura }\end{array}$ \\
\hline $\begin{array}{c}\text { Rio de Janeiro } \\
\text { Lei } n^{\circ} 1.954 / 1992 \\
\text { Lei } n^{\circ} 8.266 / 2018 \\
\end{array}$ & $\begin{array}{l}1992 \\
2018\end{array}$ & Até 3,00\% & $\begin{array}{c}\text { Iniciação Desportiva, Divulgação / Publicação / } \\
\text { Memória, Patrocínio a Equipe / Atletas e } \\
\text { Edificação Esportiva }\end{array}$ \\
\hline $\begin{array}{l}\text { Rio Grande do Sul } \\
\text { Lei } n^{\circ} 13.924 / 2012\end{array}$ & 2012 & De 5,00 a $20,00 \%$ & $\begin{array}{c}\text { Educacional Participação, Rendimento, Sócio } \\
\text { Desportiva, Infraestrutura, Desporto / Lazer / } \\
\text { Gestão e Desenvolvimento Esportivo }\end{array}$ \\
\hline $\begin{array}{c}\text { Santa Catarina } \\
\text { Lei } n^{\circ} 13.336 / 2005\end{array}$ & 2005 & Até $20,00 \%$ & Sócio Desportiva \\
\hline $\begin{array}{l}\text { São Paulo } \\
\text { Decreto } n^{\circ} \\
55.636 / 2010\end{array}$ & 2010 & Até 3,00\% & $\begin{array}{c}\text { Educacional, Participação, Rendimento, } \\
\text { Infraestrutura, Formação Esportiva / Sócio } \\
\text { Desportiva / Gestão e Desenvolvimento } \\
\text { Esportivo }\end{array}$ \\
\hline
\end{tabular}

Fonte: construção dos autores.

Identificou-se que em todos os 15 Estados, o tributo em questão é o Imposto sobre Circulação de Mercadorias e Prestação de Serviços (ICMS). O ICMS é um tributo que somente os Estados e o Distrito Federal têm competência para instituí-lo - conforme o art. 155, II, da nossa Constituição (BRASIL, 1988). Muitas vezes o ICMS é parte fundamental para a receita dos Estados e também dos seus respectivos municípios, pois sua arrecadação geralmente é utilizada para investimentos em serviços públicos essenciais como segurança, saúde, educação, 
além do esporte, como pôde ser identificado em alguns Estados. Seu cálculo varia de Estado para Estado, além de variar também de acordo com a tipologia de produtos e serviços, origemdestino, empresa, cliente, dentre outras características (SÃO PAULO, 2020).

Foi possível identificar uma variação quanto às porcentagens de isenção do ICMS em prol do esporte, com destaque para os Estados do Rio Grande do Sul e Santa Catarina. Por outro lado, as porcentagens muitas vezes não refletem valores reais captados e aplicados ao esporte, como já observado em outros estudos (MATIAS et al., 2015; NASCIMENTO, 2019; SANTOS; JUCHEM; MADURO, 2017). Outros pontos de reflexão podem envolver o fato de que a porcentagem não retrata a característica do ICMS, uma vez que este tributo varia conforme o desenvolvimento econômico e consumo produtivo de cada Estado (MATTOS; ROCHAY; TOPORCOV, 2013).

Por fim, com relação às manifestações esportivas, se esperava uma proximidade com devidas adequações com relação à realidade de cada Estado (a partir do artigo terceiro da Lei 9.615 de 1998: Desporto Educacional, Desporto de Participação, Desporto de Formação, Desporto de Rendimento, BRASIL, 1998). No entanto, em alguns Estados se estabeleceu manifestações diferenciadas, provavelmente de acordo com os seus contextos e interesses, conforme apresentado no Quadro 1.

Já com relação ao tipo de ação quanto ao seu enquadramento legal, foi observado que das 15 ações identificadas, em 13 (87\%) existe uma legislação estadual específica sobre o tema. Por outro lado, em dois Estados (13\%) as ações são regulamentadas por um decreto baseados em uma legislação maior que está relacionada ao uso de determinada tributação. Os 13 Estados com legislação específica são (em ordem alfabética): Acre, Bahia, Ceará, Goiás, Maranhão, Mato Grosso, Minas Gerais, Paraná, Pernambuco, Piauí, Rio de Janeiro, Rio Grande do Sul e Santa Catarina. Dos Estados que possuem uma legislação específica, há uma particularidade, onde os Estados do Piauí, Rio Grande do Sul e Santa Catarina possuem regulamentação através de um Fundo, ou seja, os recursos captados de determinada tributação são direcionados primeiro para um Fundo (gerenciado pelo Estado), que posteriormente, de acordo com critérios estabelecidos, são aportados em projetos e iniciativas esportivas.

Os dois Estados que regulamentam a isenção fiscal em prol do esporte através de decreto, são os Estados de São Paulo e Paraíba. Dessa maneira, esses Estados não possuem uma lei específica relacionada com isenção fiscal em prol do Esporte, mas sim, possuem uma 
Lei Geral onde há a autorização para o uso de uma arrecadação proveniente de tributo, a qual contempla uma série de áreas (Educação, Saúde, Segurança, Transportes, Esporte, dentre outros). Um ponto a ser considerado sobre decretos reguladores é que são tipos de processos normativos secundários, a depender muitas vezes da autonomia do poder executivo. Diferentemente as LIEs são criadas dentro de um processo legislativo completo envolvendo comissões, plenário, discussão e promulgação, ou seja, envolvem discussões com maior profundidade e maior participação da sociedade (SALINAS, 2012).

Sobre os tipos de proponentes, que muitas vezes são reconhecidos pela gestão de projetos e atividades esportivas que serão contempladas para o recebimento dos recursos originados a partir do aporte cedido através de isenção fiscal, existe uma certa diversificação com relação à algumas especificidades. Em cinco (33\%) Estados dos 15 identificados (Ceará, Mato Grosso, Pernambuco, Piauí e São Paulo), os proponentes são determinados como "Pessoas Jurídicas" sem fins lucrativos. No Estado do Rio Grande do Sul, os proponentes também são Pessoas Jurídicas, mas com a possibilidade de serem tanto com ou sem fins lucrativos. No Estado da Paraíba os proponentes também são Pessoas Jurídicas, mas apenas aquelas caracterizadas em seus estatutos como Federações Esportivas. No Estado de Minas Gerais, as Pessoas Jurídicas, para serem qualificadas como proponentes, deverão ser obrigatoriamente qualificadas como Organização da Sociedade Civil de interesse público (OSCIP) e no Estado do Maranhão, os proponentes poderão ser apenas os Municípios do Estado. Para outros cinco (33\%) Estados (Acre, Bahia, Paraná, Goiás e Santa Catarina) os proponentes poderão ser tanto Pessoas Jurídicas sem fins lucrativos como também Pessoas Físicas. O Estado do Rio de Janeiro possibilita que os proponentes possam ser Pessoas Jurídicas com ou sem fins lucrativos e também Pessoas Físicas.

A partir do objetivo estabelecido de apresentar um diagnóstico das Leis de Incentivo ao Esporte em um âmbito Estadual, com base nos resultados encontrados algumas considerações podem ser feitas sobre essas Políticas Públicas. Mesmo com a identificação de 15 Estados que possuem mais uma iniciativa para financiamento do esporte, o que é louvável, pode-se considerar que o orçamento para a área esportiva, seja qual for a manifestação, ainda é complexo, confuso, multifacetado e multivariável, como constatado por diversos autores (CARNEIRO et al., 2021; CASTRO, 2016; FERREIRA; FILHO, 2021). Assim, considerações mais aprofundadas sobre a existência de Leis de Incentivo ao Esporte em nível Estadual ficam limitadas neste artigo. Por outro lado, e como já citado, uma pesquisa descritiva como esta, 
que caracteriza a existência de demais possibilidades de isenção fiscal em prol do esporte, pode servir de base para possíveis reflexões do desenvolvimento esportivo no Brasil e suas políticas públicas.

Logo, apesar de 15 Estados representarem 87\% das unidades da república brasileira, ao analisar com mais precisão, percebe-se que sete Estados somados são das regiões Sudeste e Sul. Ainda cabe destacar a baixa existência de ações envolvendo isenção fiscal para o Esporte em Estados das regiões Norte e Centro-Oeste. Tais reflexões podem ser relativas, pois os Estados podem ter certa autossuficiência estatal para o esporte ou limitações quanto à possibilidade de destinar parte da arrecadação para uma determinada atividade, neste caso, o esporte.

Aliás, agregando ao tema autossuficiência estatal e possibilidade de isenção fiscal, o que de certa forma diminui a arrecadação pelo poder público, observou-se que 13 Estados possuem suas legislações para normatização de isenção fiscal (ICMS) em prol do esporte. Conforme apresentado por Bobbio e Bovero (2000), a existência de leis remetem à expressão da vontade coletiva, definidora dos direitos e deveres de todos os cidadãos, impedindo que fosse confundida com a vontade pessoal do governante. Fato é que nos Estados que permitem isenção fiscal em prol do esporte através de Decreto, existirá o risco de descontinuidade da política pública, conforme fatos ocorridos em 2021, onde a Secretaria da Fazenda e Planejamento do Estado de São Paulo determinou que, excepcionalmente nos anos de 2021, 2022 e 2023, a submissão de projetos esportivos para adesão à Lei Paulista de Incentivo ao Esporte foi suspensa (SÃO PAULO, 2021). Para que tal medida fosse realizada com uma lei, o processo seria bem mais complexo, sendo que obrigatoriamente a decisão teria de passar pelo debate nas instituições e funções públicas (BOBBIO; BOVERO, 2000). Ao mesmo tempo, os Estados brasileiros são dependentes do ICMS, e devido ao contexto pandêmico provocado pelo COVID-19, tais decisões como a de suspender a possibilidade de isenção deste imposto para projetos esportivos são, de algum modo, compreensíveis.

De certa forma, tal diagnóstico apresentado neste estudo provoca diversos questionamentos. Essa opção de política pública é efetiva? Nas ações estaduais existem as mesmas características da LIE Federal? Como, por exemplo, desiquilíbrio entre aprovação pelo órgão público e a captação de recursos junto a iniciativa privada ou até o favorecimento de uma manifestação esportiva em detrimento das outras? E, por fim, qual o papel dos Estados na Política Nacional do esporte no Brasil? Qual o papel dos Estados no sistema esportivo 
brasileiro? As duas últimas perguntas vêm de encontro ao grande questionamento que diferentes autores têm provocado em suas publicações no sentido de não existir de forma mais clara um sistema esportivo no país (BÖHME; BASTOS, 2016; MAZZEl et al., 2015; MENDES; CODATO, 2015; MEZZADRI et al., 2015) - sendo um sistema composto por partes interrelacionadas que se destinam a realizar objetivos claramente definidos, sendo que cada parte possui seu papel claramente definido (CHELLADURAI, 2009; DE BOSSCHER et al., 2015; LYLE, 1997; MAZZEl et al., 2020). A ausência de um sistema mais organizado no Brasil faz com que muitas Políticas Públicas, como as Leis de Incentivo fiscal em nível Estadual, se tornem muitas vezes improdutivas ou são produtos de sobreposições de investimento proporcionando um desenvolvimento esportivo desequilibrado.

\section{CONCLUSÕES}

Esse estudo objetivou diagnosticar as ações relacionadas com isenções fiscais (Leis de Incentivo) em prol do Esporte no âmbito Estadual. Foi possível identificar alguns padrões de Estado para Estado que possuem tal iniciativa, como por exemplo o provimento de recursos para projetos esportivos a partir do tributo ICMS. Ao mesmo tempo, também foi possível identificar que em cada Estado identificado há particularidades, que vão desde o ano que se iniciou tal ação, porcentagens de ICMS que podem ser destinadas pela iniciativa privada ao esporte, tipos de proponentes e manifestações esportivas a serem contempladas.

Para ampliar a visão sobre esse tema, será necessário aprofundar a pesquisa a fim de entender os dados relacionados ao quantitativo de projetos apresentados, a captação dos recursos, quantitativo de recursos investidos, entre outras variáveis, para assim ser possível avaliar de forma mais aprofundada as características dessas Políticas Públicas estaduais e seus benefícios para o desenvolvimento esportivo, sejam nos Estados, seja no esporte do Brasil como um todo.

\section{REFERÊNCIAS BIBLIOGRÁFICAS}

BASTIDAS, Marina Gallego; BASTOS, Flávia Cunha. A lei de incentivo fiscal para o desporto e a formação de atletas no Brasil. Revista intercontinental de gestão desportiva, v. 1, n. 2, p. 111-121, 2011.

BOBBIO, Norberto; BOVERO, Michelangelo. Teoria geral da política: a filosofia política e as 
lições dos clássicos. Rio de Janeiro: Campus Elsevier, 2000.

BÖHME, Maria Tereza Silveira; BASTOS, Flávia Cunha (OrgS.). Esporte de alto rendimento: fatores críticos - gestão - identificação de talentos. São Paulo: Phorte, 2016.

BRASIL. Constituição da República Federativa do Brasil de 1988. Brasília, DF: Senado Federal: Centro Gráfico, 1988.

BRASIL. Lei $\mathbf{n}^{\circ} \mathbf{1 0 . 2 6 4}$, de 16 de julho de 2001, acrescenta inciso e parágrafos ao art. 56 da Lei no 9.615, de 24 de março de 1998, que institui normas gerais sobre desporto. 2001. Disponível em: <http://www.planalto.gov.br/ccivil_03/Leis/LEIS_2001/L10264.htm>. Acesso em: 31 out. 2012.

BRASIL. Lei $\mathbf{n}^{\circ}$ 10.891, de 9 de julho de 2004, que Institui o Bolsa Atleta. 2004. Disponível em: <http://www.planalto.gov.br/ccivil_03/_ato2004-2006/2004/lei/l10.891.htm>. Acesso em: 24 ago. 2014.

BRASIL. Lei $\mathbf{n}^{\circ}$ 11.438, de 29 de Dezembro de 2006, dispõe sobre incentivos e benefícios para fomentar as atividades de caráter desportivo e dá outras providências. 2006. Disponível em: <http://www.esporte.gov.br/arquivos/ministerio/legislacao/ lei1143829122006.pdf>. Acesso em: 31 out. 2012.

BRASIL. Lei $\mathbf{n}^{\circ}$ 9.615, de 24 de Março de 1998, institui normas gerais sobre desporto e dá outras providências. $1998 . \quad$ Disponível em: <http://www.planalto.gov.br/ ccivil_03/leis/19615consol.htm>. Acesso em: 24 ago. 2014.

CARNEIRO, Fernando Henrique Silva e colaboradors. O financiamento federal do esporte de alto rendimento no ciclo olímpico e paralímpico Rio 2016. Revista brasileira de ciências do esporte, v. 43, e031919, 2021.

CASTRO, Suélen Barboza Eiras. Políticas públicas para o esporte e lazer e o ciclo orçamentário brasileiro (2004-2011): prioridades e distribuição de recursos durante os processos de elaboração e execução orçamentária. 2016. 383f. Tese (Doutorado em Educação Física). Universidade Federal do Paraná, Curitiba, PR, 2016.

CHELLADURAI, Packianathan. Managing organizations for sport and physical activity: a systems perspective. Scottsdale, USA: Holcomb Hathaway, 2009.

DE BOSSCHER, Veerle; SHIBLI, Simon; WESTERBEEK, Hans; VAN BOTTENBURG, Maarten. Successful elite sport policies: an international comparison of the sportspolicy factors leading to international sporting success (SPLISS 2.0) in 15 nations. Aachen, Germain: Meyer \& Meyer Verlag, 2015.

FERREIRA, Alan de Carvalho Dias; REPPOLD, Alberto Reinaldo. Um método para o mapeamento e gestão de dados do financiamento do esporte de alto rendimento no Brasil. Brazilian journal of development, v. 7, n. 7, p. 71307-71321, 2021. 
LYLE, John W. B. Managing excellence in sports performance. Career development international, v. 2, n. 7, p. 314-323, 1997.

MALHOTRA, Naresh K. Pesquisa de marketing: uma orientação aplicada. 6. ed. Porto Alegre, RS: Bookman, 2011.

MATIAS, Wagner Barbosa e colaboradores. A lei de incentivo fiscal e o (não) direito ao esporte no Brasil. Movimento, v. 21, n. 1, p. 95-110, 2015.

MATTOS, Enlinson; ROCHAY, Fabiana; TOPORCOV, Patrícia. Programas de incentivos fiscais são eficazes evidência a partir da avaliação do impacto do programa nota fiscal paulista sobre a arrecadação de ICMS. Revista brasileira de economia, v. 67, n. 1, p. 97-120, 2013.

MAZZEI, Leandro Carlos e colaboradores. High-performance judo: identification of the organisational factors influencing international sporting success. Managing sport and leisure, v. 25, p. $1-18,2020$.

MAZZEI, Leandro Carlos e colaboradores. High performance sport in Brazil: structure and policies comparison with the international context. Gestión y política pública, v. Temático, n. Políticas Públicas del Deporte, p. 83-111, 2015.

MEIRA, Tatiana de Barros; BASTOS, Flávia da Cunha; BÖHME, Maria Tereza Silveira. Análise da estrutura organizacional do esporte de rendimento no Brasil: um estudo preliminar. Revista brasileira de educação física e esporte, v. 26, n. 2, p. 251-262, 2012.

MENDES, Alessandra; CODATO, Adriano. The institutional configuration of sport policy in Brazil: organization, evolution and dilemmas. Revista de administração pública, v. 49, n. 3, p. 563593, 2015.

MEZZADRI, Fernando Marinho e colaboradores. Sport policies in Brazil. International journal of sport policy and politics, v. 7, n. 4, p. 655-666, 2015.

NASCIMENTO, Amanda Sousa. A lei federal de incentivo ao esporte: análise do perfil dos proponentes e dos financiadores esportivos (2007-2016). 2019. 146f. Dissertação (Mestrado em Educação Física). Universidade Estadual de Campinas, Campinas, PR,2019.

SALINAS, Natasha Schmitt Caccia. Legislação e políticas públicas: a lei enquanto instrumento de ação governamental. 2012. 234f. Tese (Doutorado em Direito). Universidade de São Paulo, São Paulo, 2012.

SANTOS, Edmilson Santos dos; JUCHEM, Luciano; MADURO, Luiz Alcides Ramires. Esporte rendimento, renúncia fiscal e lei de incentivo ao esporte. Journal of physical education, v. 28, n. e2834, p. 1-13, 2017.

SÃO PAULO. O que é e como é investido o ICMS. 2020. Disponível em: $<$ https://portal.fazenda.sp.gov.br/Noticias/Paginas/O-que-é-e-como-é-investido-oICMS.aspx>. Acesso em: 20 jul. 2021. 
SÃO PAULO. Resolução da Secretaria da Fazenda e Planejamento $\mathbf{n}^{\circ} \mathbf{4}$ de $\mathbf{1 4}$ de Janeiro de 2021. 2021. Disponível em: <https://legislacao.fazenda.sp.gov.br/Paginas/Resolução-SFP-4de-2021.aspx>. Acesso em: 24 jul. 2021.

SECCHI, Leonardo; COELHO, Fernando de Souza; PIRES, Valdemir. Políticas públicas: conceitos, casos práticos, questões de concurso. 3. ed. São Paulo: Cengage Learning, 2020.

VERGARA, Sylvia Constant. Projetos e relatórios de pesquisa em administração. 12. ed. São Paulo: Atlas, 2010.

\section{Dados da primeira autora:}

Email: sabrinavitoriome@gmail.com

Endereço: Rua Pedro Zaccaria, 1300, sala LA-525D, Jardim Santa Luzia, Limeira, SP, CEP: 13484350, Brasil.

Recebido em: 29/10/2021

Aprovado em: 03/12/2021

\section{Como citar este artigo:}

VITÓRIO, Sabrina de Lima e colaboradores. Diagnóstico das leis estaduais de incentivo ao esporte no Brasil. Corpoconsciência, v. 25, n. 3, p. 222-236, set./ dez., 2021. 